\title{
Cloud Library Framework for Ethiopian Public Higher Learning Institutions
}

\author{
Tilahun Shiferaw \\ Department of Information Science, College of Computing and Informatics, Haramaya University \\ P.O.Box, 138, Haramaya, Ethiopia \\ Email: shiferaw.tilahun@gmail.com \\ Dr. Patrick D. Cerna \\ Department of Information Technology, College of Computing and Informatics, Haramaya University \\ P.O.Box 335, Haramaya, Ethiopia \\ Email: dr.patrickcerna@gmail.com
}

\begin{abstract}
The ever increasing users' information need of electronic resources forced librarians to increase their effort of collecting, organizing, preserving and disseminating huge amount of electronic materials, which require state-of-the-art infrastructures so that the electronic resources be deployed easily, quickly and economically. Cloud library is the best option for libraries; especially where electronic library services divide is highly visible, like the Ethiopian higher learning institutions. Such library system allows the establishment of information technology infrastructure on demand and lowers the difficulty of control mechanism. The integration of existing library services can be implemented by clustering current library environment. The methodology employed for this work include a rigorous analysis of a recent research on one point cloud library service as an alternative to e-service provision and management. In addition, to designing a final framework a researchers conduct a survey research which helps to identify the stakeholders view on cloud library services, the model required and services needed. Questionnaire was used to collect data from purposively selected academic libraries. The selection was centered on the generation of universities namely $1^{\text {st }}, 2^{\text {nd }}$ and $3^{\text {rd }}$ generation.
\end{abstract}

Index Terms-Cloud Library, Integrated library, Cloud library framework, e-service divide, clustered cloud library, Higher learning Institutions.

\section{INTRODUCTION}

Cloud library is a model for enabling convenient and on-demand network access to a shared pool of configurable electronic resources, such as E-journals, Institutional repositories, Digital libraries, and other library services that can be rapidly provided and released with minimal effort of service providers [1]. These authors also made clear that cloud library is endowed with essential characteristics, among others on-demand self-service, broad network access and resource pooling. Thus, its implementation to effectively share the available e-resources is highly advantages in a situation like Ethiopia, where electronic resources divide among the academic libraries is very high [2]. Today's libraries are facing the challenges posed by a diverse and rapidly expanding information universe. Increased user expectations for faster and easier access to relevant information go hand in hand with institutional demands for increased operational efficiency.

Resource sharing, integrated library system, financial problems, lack of IT resources and shortage of skilled human resources were identified to be the major problems of all libraries in Ethiopia [3]. Because of these the aforementioned problems, the academic community of Ethiopian universities face obstacles to complete the tasks that involve library resources. Currently, most academic libraries in Ethiopian could not provide all the services requested by their patrons. Due to high initial cost as well as maintenance cost, establishing digital library for every university is hardly possible under current situation, given the fact that with small amount of budget allocated to them university libraries in Ethiopia are struggling to continue providing services to users. However, the costs required to establish a library of $21^{\text {st }}$ century can be significantly reduced if cloud system is implemented. Thus, there should be a need to establish cloud library, which can be administrated by one institution in cooperation with all the stakeholders, whereby all the available e-resources can be placed at the cloud and then shared among all hosted universities [4]. The main aim of this article is to indicate the benefits of a clustered cloud library connected with network and present the service of infrastructure, platform and software that balances the e-resource access by users (students, teachers and researchers) of all public universities in Ethiopia.

In line with the themes of the ICT-Ethiopia, namely einfrastructures, this paper is presented to show the current situation of Ethiopian higher learning institutions' libraries and the way forward to meet the ever increasing need of the users. From this paper, the concerned bodies would find out the current status of academic libraries in Ethiopian and could also see the similarities and 
differences of the approach to be adopted in their countries.

The mechanisms in which services were delivered between universities in Ethiopia are varied. Thus frequency usage of e-library services at each university were indicated poor. The available resource and services in different universities in Ethiopia were similar in feature, purpose and objectives but differently operated in different academic institutions which lead to redundancy and wastage of resources. Generally it is quite interesting to note that at the study sites the availability of e-library services, respondents' satisfaction level with their university service and sufficiency of e-database, e-journal, institutional repository and digital library services in universities were very low.

Since cloud library is more economical and cost effective than the traditional computing methods, librarians were highly supportive on the idea of cloud library establishment and are wishing to have various services that can be implemented on the cloud platform.

In this research papers, the authors proposed a framework utilization cloud-computing technologies to provide e-library services for Ethiopian higher learning institution. Cloud Library Service Model contains four layers (User Interface, software as a service (SaaS), Platform as a service (PaaS), and Infrastructure as a service (IaaS) and three modules (User log database, system security, and service management).

\section{OBJECTIVES}

\section{A. General Objective}

The objective of this study was to propose a cloud library framework for Ethiopian higher learning institutions.

\section{B. Specific Objectives}

The concern of the study is to quantify the usage of cloud library applications in public higher institution libraries of Ethiopia. The following specific objectives are found to be of central importance in this paper:

$\checkmark \quad$ To scrutinize possibilities for implementing cloud libraries in Ethiopia

$\checkmark$ To indicate the benefit of cloud library service,

$\checkmark$ To demonstrate library services to be provided through cloud library

$\checkmark$ To audit the level of using cloud library in Ethiopia

\section{RELATED LITERATURE}

\subsection{Cloud Computing}

Cloud computing is a model for enabling convenient, on-demand network access to a shared pool of configurable computing resources (e.g., networks, servers, storage, applications, and services) that can be rapidly provisioned and released with minimal management effort or service provider interaction [14]. According to the National Institute of Standards and Technology (NIST) definition (2009), Cloud computing is a model for enabling ubiquitous, convenient on-demand network access to a shared pool of configurable computing resources (e.g., networks, servers, storage, applications, and services) that can be rapidly provisioned and released with minimal management effort or service provider interaction. Cloud computing is a model for delivery of resources as a service [15].

Cloud computing is a style of computing in which massively scalable and elastic IT-enabled capabilities are delivered as a service to external customers using Internet technologies [16]. Cloud Computing is the improvement of Distributed Computing, Parallel Computing, Grid Computing and Distributed Databases. And the basic principle of Cloud Computing is making tasks distributed in large numbers of distributed computers but not in local computers or remote servers [17]. The term "Cloud Computing" is the computing services in Information Technology like infrastructure, platforms, or applications could be arranged and used through the internet. Infrastructure upon which cloud is built upon is a large scaled distributed infrastructure in which shared pool of resources are generally virtualized, and services which are offered are distributed to clients in terms of virtual machines, deployment environment, or software. Hence it can be easily concluded that according to the requirements and current workloads, the services of cloud could be scaled dynamically. As many resources are used, they are measured and then the payment is made on the basis of consumption of those resources [18]. Cloud computing provides a way for businesses to increase capacity and quality without investing in new infrastructure, licensing new software or training personnel [19]. Cloud computing shares characteristics with autonomic computing, peer to peer, grid computing, client server model, mainframe computer and utility computing. It has various open source resources which gives different platform for better computing utilization [20].

\subsection{Cloud Computing impact to libraries}

Cloud computing encourages libraries and their users to participate in a network and community of libraries by enabling them to reuse information and socialise around information. The Cloud computing techniques and methods applied to libraries, not only can improve the quality of services and utilisation of resources, but also can make more extensive use of cloud computing to our work life [21].

Cloud computing simplifies management of collective resources use, remote access for multiple user selection, providing the necessary tools at some point of the training process. Collections of resources may be accessed through "Software as Services (SaaS)" [22].

When library systems are deployed as open cloud solutions then the library community itself can step up to create extensions to their core services and more importantly share them throughout the community using 
cloud solutions. libraries can get out of the business of technology and focus on collection building, patron services and innovation. Servers can be decommissioned and no longer require replacement every five years (or less). Staff no longer has to maintain the complex software stack necessary to run local systems and worry about compatibility of the stack during upgrades. Instead technical skills can be re-deployed for extending cloud services into their environment and their environment into other cloud services [16].

\section{METHODOLOGY}

Currently there are thirty-five universities established in different parts of Ethiopia. The authors clustered the universities into four groups based on their proximity to each other. Those universities are classified in to 3 generations based on their establishment time. Ten of them were relatively old and categorized as the first generation, eleven were established somewhat later and categorized as the $2^{\text {nd }}$ generation and the remaining were newly established and categorized as third generation. The $1^{\text {st }}$ and $2^{\text {nd }}$ generation libraries were experienced on developing and using e-library service and relatively advanced on the use. Therefore, in the study two universities were purposively selected from each generation based on their level of e-library service provision.

Various techniques and tools were analyzed, modified and used from previous works. Besides, different personnel in the library including library director, librarians, developers and ICT directors were interviewed for better understanding of the current ICT utilization strategy, effectiveness and efficiency of service delivery and also their recommendation for better service delivery. Table 1 presents the study population, generation, and target group.

Table 1. University Profile and Target Group

\begin{tabular}{|c|c|c|c|}
\hline Sampled university & $\begin{array}{l}\text { Population } \\
\text { size }\end{array}$ & $\begin{array}{c}\text { Sample } \\
\text { size }\end{array}$ & $\begin{array}{l}\text { Sampling } \\
\text { techniques }\end{array}$ \\
\hline \multirow{2}{*}{$\begin{array}{c}\text { Addis Ababa } \\
\text { university }\end{array}$} & 23 & 23 & \multirow[t]{2}{*}{ Availability } \\
\hline & 6 & 6 & \\
\hline \multirow{2}{*}{$\begin{array}{l}\text { Haramaya } \\
\text { university }\end{array}$} & 6 & 6 & \multirow[t]{2}{*}{ Availability } \\
\hline & 3 & 3 & \\
\hline \multirow[t]{2}{*}{ Jimma University } & 14 & 14 & \multirow[t]{2}{*}{ Availability } \\
\hline & 3 & 3 & \\
\hline \multirow{2}{*}{$\begin{array}{l}\text { Hawassa } \\
\text { University }\end{array}$} & 8 & 8 & \multirow[t]{2}{*}{ Availability } \\
\hline & 4 & 4 & \\
\hline \multirow{2}{*}{$\begin{array}{c}\text { Mizan Tepi } \\
\text { university }\end{array}$} & 6 & 6 & \multirow[t]{2}{*}{ Availability } \\
\hline & 1 & 1 & \\
\hline \multirow[t]{2}{*}{ Jigijiga university } & 4 & 4 & \multirow[t]{2}{*}{ Availability } \\
\hline & 2 & 2 & \\
\hline Total & 80 & 80 & \\
\hline
\end{tabular}

Table 2. Sample Size and Sampling Techniques

\begin{tabular}{|c|c|c|}
\hline $\begin{array}{c}\text { Sampled } \\
\text { university }\end{array}$ & Generation & Target group \\
\hline $\begin{array}{c}\text { Addis Ababa } \\
\text { university }\end{array}$ & $1^{\text {st }}$ generation & Librarian \\
\cline { 3 - 3 } & & IT professional \\
\hline $\begin{array}{c}\text { Haramaya } \\
\text { university }\end{array}$ & $1^{\text {st }}$ generation & Librarian \\
\cline { 3 - 3 } & & IT professional \\
\hline Jimma University & $2^{\text {nd }}$ generation & Librarian \\
\cline { 3 - 3 } & & IT professional \\
\hline $\begin{array}{c}\text { Hawassa } \\
\text { University }\end{array}$ & $2^{\text {nd }}$ generation & Librarian \\
\cline { 3 - 3 } $\begin{array}{c}\text { Mizan Teppi } \\
\text { university }\end{array}$ & $3^{\text {rd }}$ generation & IT professional \\
\cline { 3 - 3 } & & Librarian \\
\hline Jigijiga university & $3^{\text {rd }}$ generation & IT professional \\
\cline { 3 - 3 } & & Librarian \\
\hline
\end{tabular}

There are 35 universities established in different parts of Ethiopia. Therefore, in the study 6 out of 35 universities were considered. A questionnaire survey was used for the collection of data from an availability sample of 80 library professionals drawn from 6 university libraries of Ethiopia.

\section{A. Technology Description}

Due to different factors, it is obvious that e-library system in Ethiopian higher learning institution is currently not well developed and can be said it is at a very early stage. Cloud based library technology, coupled with different services such as online e-resource sharing system, integrated library management system, digital repositories, open url resolver, citation management, web communication tools and database management system delivers more flexibilities and efficient resource utilization among the universities. The figure below shows a general layout of the cloud-based library service model of cloud computing with an interface layer in order to control users' access to different services.

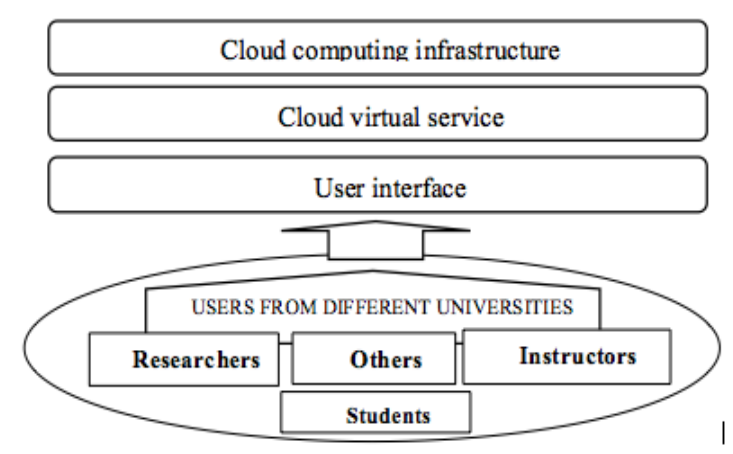

Fig.1. Cloud-Based Service model

Applying the cloud-based architecture deployment of e-library services to university library system will result in providing the required services in the appropriate layer through the interface [5]. Using this architecture will enhance the quality of service to add more contents. 


\section{B. Business Benefits}

Considering the presented issues of e-library services development in Ethiopian higher learning institutes and a focus on library resource sharing, various solutions can be provided. However, the researchers suggest using an integrated clustered community cloud library system for sharing of e-resources. Being supported by adequate strategies and policies, it would provide solution for existing problems, like lack of resource sharing, poor eresource management, lack of good preservation, inefficient utilization of resources, duplication of resources and poor library projects collaborations among universities. Centralized cluster libraries should be established as an e-library resource center being designed or constructed with low storage costs, maintenance, and easily sharing the resources among clustered clouds [6]. Each cluster in a given location is considered as a community cloud for universities grouped under that cloud instead of having an e-library system for each academic institution, which requires high investment to install state-of-the-art infrastructure and fast Internet connection.

The reduction of duplicated resources would also reduce the storage space needed and thus the costs since only one copy would be stored in the cloud and could be accessible by users based on their privileges regardless of their institutions [7][8].

\section{Development}

To identify the potential cloud library services that can be provided to university community, the authors started by analyzing the requirements of universities by using questionnaire, interview and observation made at companies and universities with best cloud service practices. The analysis was based on the interviews of library directors of the selected universities as well as reviewing best cloud library service practices of universities around the world [9] [10] [11] [12].

After identifying users cloud library service and model need, the authors examined the challenges and opportunities of the cloud computing models in terms of economic values, management issues and security by reviewing different cloud service models [13]. Based on the geographical location, the authors designed a framework that significantly benefits all the universities. Users could access the library services of all cloud system through Meta search engine interface

\section{RESULTS}

\section{A. Need for Cloud Library services}

The result of the study revealed that majority of the librarians from the universities considered for the study strongly agreed on the need of Cloud library services as depicted in the figure below.

The result of the study revealed $59.7 \%$ of the respondents strongly agreed that cloud system will solve their libraries service delivery problems. Moreover, $16.8 \%$ of them agreed that cloud library is the best solution to improve the library environment. Thus, it can be said that cloud library is a solution for better delivery of services for users compared to the traditional library and hence it can be concluded cloud library is the way forward for Ethiopian higher learning institutions and librarians are motivated and ready to accept the cloud library technology if implemented.

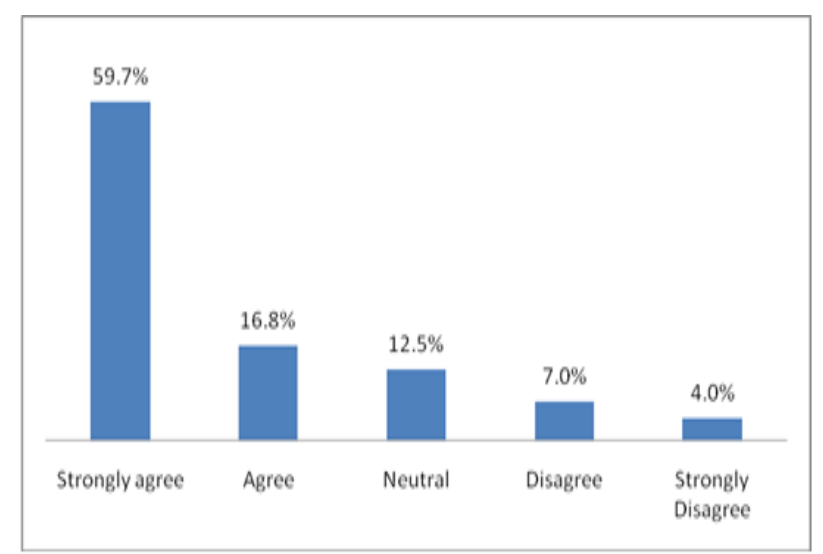

Fig.2. Cloud library is the best solution

\section{B. Cloud library development model}

In this regard, respondents were asked to select a model to which they are most interested. For any organizations to adopt cloud library, first there should be an understanding about the models of cloud technology. A summary of the response from the study participants is depicted below (figure 3 ).

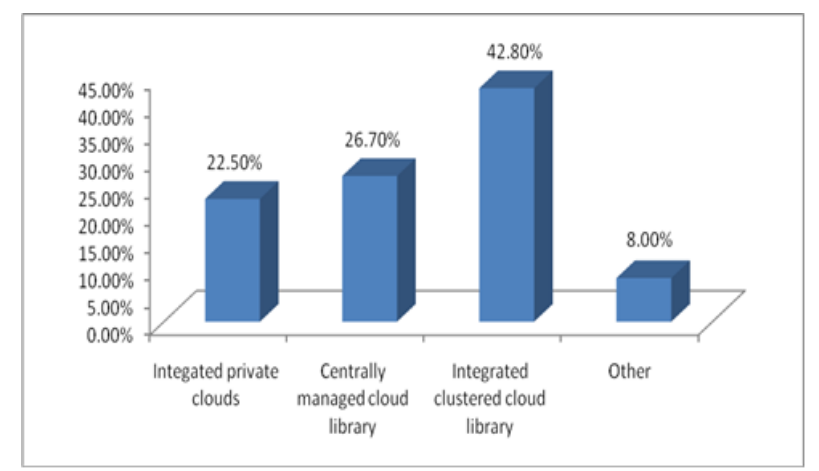

Fig.3. Cloud Computing Deployment models in libraries

It was found that $42.80 \%$ of the respondents preferred integrated clustered cloud computing library model, followed by centrally managed cloud library (26.70\%) and integrated private clouds $(22.50 \%)$.

\section{Expectation of Library Services on Cloud}

The librarians were asked questions to determine which services on cloud library is more needed by their university libraries. Accordingly, the respondents identified access to library collection, current awarness service and selective dismination of information services through cloud communication tools, management of scholarly documents, and library software, were the main 
services needed to be included on the cloud as presented in figure 4.

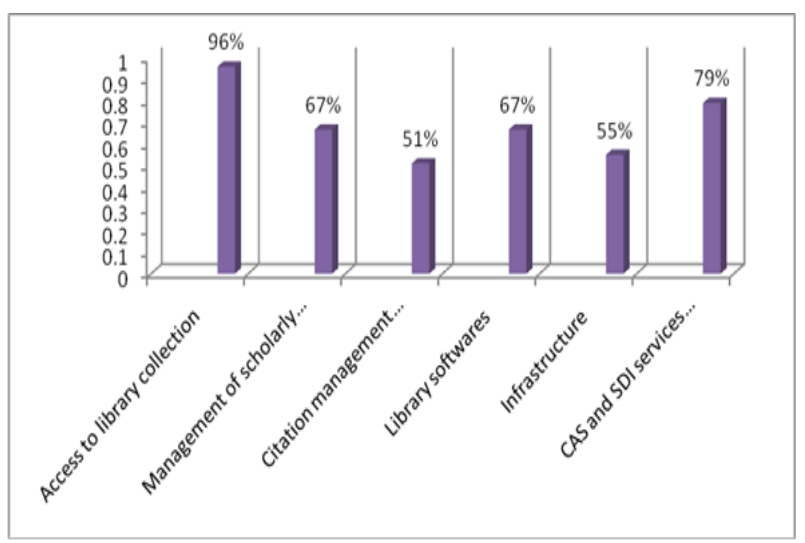

Fig.4. Expectations of library services through cloud library

The result of the study showed that librarians' interest is diverse when it comes to the type of services under cloud library. However, the vast majority of the respondents, $95 \%$, preferred access to library collections and $51 \%$ of them indicated that citation management software. A little over $67 \%$ said that management of scholarly documents, $79 \%$ of respondents said current awareness services (CAS) and selective dissemination of information (SDI) services through cloud based communication tools. Besides, $67 \%$ and $55 \%$ of respondents respectively said library software and infrastructure are their expectation on cloud library.

\section{PRoposed Framework OF Clustered Cloud LIBRARY}

The authors proposed to clustered universities in to four community's cloud, which are inter-connected. The categories of universities in to different communities are based on their proximity to each other. The service and application might be the same, which means one system should have a copy of the others. In addition, services in all cloud community can be accessed by all communities through the Meta search engine interface. Thus, if one system (cloud services) fails the rest works and other service is not interrupted. However, system continuity should be guaranteed by the commitment of responsible institutions at each cloud, and should be supported by disaster recovery plans and testing. Care should be taken to ensure the reputation and sustainability of the service within the communities in the cloud and also externally.

Hence, if university libraries that geographically situated closer to each other collaborate and preserve their resources under one cloud, it forms a collaborative system. It can be defined as "a means through which multiple institutions work together and pool their resources to manage significant portion of their holdings". They offer a shared space in which collections deposited by different libraries are maintained under a common agreement. They are included under a common control system, subjected to common standards. Their service and resource delivery is managed by one institution.

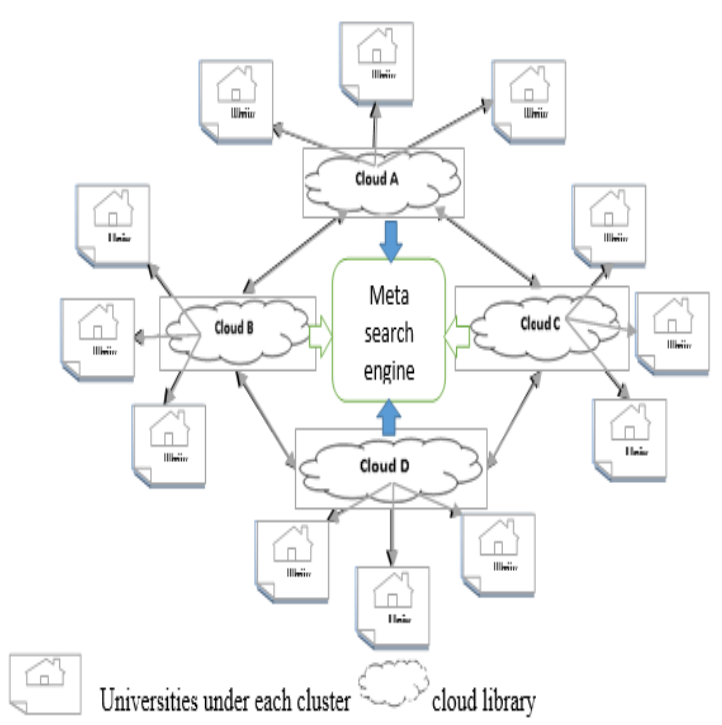

Fig.5. Proposed cloud library framework for EPHLI

The institutions with common objective regarding their less used resources and services can join hands to form a collaborative cloud library. It should be noted that for the success of collaborative system, there is a need for unwavering commitment by the participating libraries.

In a successful collaborative system, the participating libraries will not only share the resources, services and the cost involved but also should share the approach to the collection in terms of growth, management and access Collaborative effort definitely provides more efficient use of resources.

\section{PROPOSED LIBRARY SERVICES}

The presented framework contains four layers (User Interface, software as a service (SaaS), Platform as a service (PaaS), and Infrastructure as a service (IaaS) and three modules (User log database, system security, and service management).

User Interface Layer: A user Interface represents system interaction Management System since it acts as an interface between the user and the Cloud content.

User Portals: provide an access path to specific web applications or services since everything is located on the web and can be accessed using a network connection

Service Catalog: contains different types of services with detailed information about the additional access information, such as at what layer the service is located and who can access this specific service level which may be in one of the three other layers, namely SaaS, PaaS, or IaaS.

Service Repository: composed of different services like software, e-resources etc. categorized and arranged depending on the service name and access 
SaaS Layer: This layer provides access to hosted programs, applications or tools on the Cloud.

PaaS Layer: This layer provides access to different platforms- OPAC, Integrated library system, Inter library loan system and similar platforms.

The IaaS: On this service the user can deal with the fine details of the virtualization with some limitation which makes the virtualization step set in this level.

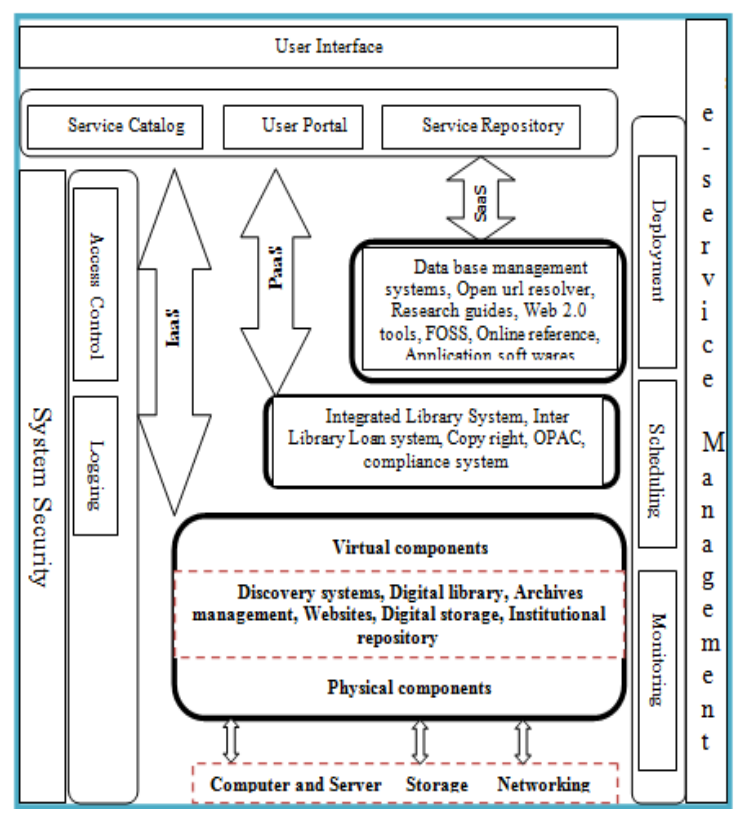

Fig.6. Cloud library service model

\section{CONCLUSION}

The present technological development and economic situation force organizations to consider adopting cloud technology. Universities have begun to take the initiative of cloud library establishment and computing and there are proofs that show significant expense minimization due to the implementation of cloud solutions. To meet the objective of the study, the authors considered the pros and cons of cloud architecture and proposed a clustered cloud library framework for EPHLIs. Moreover, the authors also addressed different cloud issues, like cloud deployment types, service delivery models and related concepts. Given the potential benefits of using clustered cloud library in library environments, it is concluded that the limitations of the current library service delivery system in EPHLIs can be solved if is implemented. The finding of the study showed that hybrid cloud computing is the best choice for deployment in the universities because it gives the combined benefit of private and public clouds.

The proposed framework would be used as a road map for further studies, which the researchers are planning to carry out soon. Cloud library would be the next major break-through in IT revolution and thus the authors strongly recommend that it is high time to start cloud libraries in Ethiopian higher institutions. Based on the pace at which IT development is moving globally in general and in Ethiopia in particular, as well as considering the attention given to the expansion of higher education in Ethiopia and the visible significant developments in ICT, the authors are optimistic that cloud library will be implemented in five years to come as the finding of this research surely contribute to enhance the initiatives started.

\section{ACKNOWLEDGEMENT}

The authors wish to thank the participating universities who took take part and in particular the target who share relevant information and time.

\section{REFERENCES}

[1] Mell P. and Grance T. (2009). "Draft NIST working definition of cloud computing," 2009.

[2] Shiferaw T. and Jimma W. "Cloud Library for Minimizing E- library services divide among Ethiopian Public Higher Learning Institutions" European Academic Research, 2015, 13663-13680.

[3] MOE "Education statistics annual abstract," Ministry of Education, Adis Abeba, November, 2013.

[4] G. L.A, "Human and physical environmental factors affecting students' utilization of library and information services in colleges of education libraries in Nigeria," American International Journal of Research in Humanities, pp. 8-16, 2014.

[5] M. Goldner, "Winds of change: libraries and cloud computing," 2010.

[6] Lohr, "Google and I.B.M Join in 'Cloud Computing' Research," The New York Times.

[7] D. Kohl, "Resource sharing in a changing Ohio environment." Library trends, vol. 3, no. 45, pp. 435-447, 2009.

[8] H. M, "A Reference Model for Developing Cloud Applications," 2012.

[9] J. Jordan, "Climbing Out of the Box and Into the Cloud: Building Web-Scale for Libraries," vol. 1, p. Journal of Library Administration, 2012.

[10] Ghiselli, C., \& Padula, M, "A unified access to extract knowledge from heterogeneous web archives," Online Information Review, vol. 5, no. 25, pp. 299-310, 2011.

[11] R. Gaur, "Model framework for reengineering of management libraries" University News, pp. 1-6, 2010.

[12] D. a. S. M. Galvin, "Avoiding the death zone: choosing and running a library project in the cloud," Library $\mathrm{Hi}$ Tech, vol. 3, no. 30, pp. 418-427, 2012.

[13] Catteddu, D. and Hogben, G., "Cloud Computing: benefits, risks and recommendations for information security," European Network and Information Security Agency, 2011.

[14] J. Geelan, "Twenty-one experts define cloud computing," Cloud Computing Journal, vol.4, pp. 1-5, 2009.

[15] Mell, Peter and Grance, Timothy. "The NIST Definition of Cloud Computing." National Institute of tandards and Technology, (2009). Accessed March 4, 2015.http://csrc.nist.gov/publications/nistpubs/800145/SP800-145.pdf.

[16] G. Matt. (2010). Winds of change: Libraries and cloud computing. OCLC Online Computer Library Center. [Online]. $\quad$ pp. 5. Available:http://www.oclc.org/content/dam/oclc/events/20 11/files/IFLA-windsof-change-paper.pdf. 
[17] S. Rupesh and K. Gaurav. (July 2011). Cloud computing in digital and university libraries. Global Journal of Computer Science and Technology. 11(12). pp. 37.

[18] Singh, H. (2015). A Review of Cloud Computing. Security Issues. International Journal of Education and Management Engineering. MECS Publishing. Vol. 5, 3241.http://doi.org/10.5815/ijeme.2015.05.04.

[19] E. Craig, M. Diana, and T. Florence, "Cloud computing an overview," MIS 641, pp. 6, 2009.

[20] Alam, I., Panday M. and Rautary, S.S. (2015). A Comprehensive Survey on Cloud Computing. International Journal of Information Technology and Computer Science. MECS Publishing. Vol. 02, 68-79. http://doi.org/10.5815/ijitcs.2015.02.09.

[21] Bhattacharjee, N., \& Purkayastha, S. D. A. S.(2013). Cloud Computing and Its Application to Libraries. eLibrary Science Research Journal. 1(7), 1-6.

[22] Deka, G. C., \& Chandra, D. G. (2016). Library Automation in Cloud Library Automation in Cloud, (SEPTEMBER 2013). Conference Paper. http://doi.org/10.1109/CICN.2013.104. several research papers in reputable journal publication. He is a member of African library association.

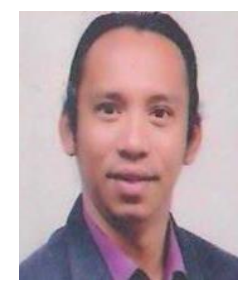

Dr. Patrick D. Cerna is an Assistant Professor in Department of Information Technology, College of Computing and Informatics in Haramaya University, Ethiopia. He is a member for some of the prestigious IS/IT international organization e.g. IEEE Computer Society, Association of Computing Machinery (ACM), Association of Information Systems (IS), International Association of Computer Science and Information Technology (IACSIT) and Institute of Advanced Engineering and Science (IAES). He has published several research papers in reputable journal publication including in the International Journal of Information Technology and Computer Science under MECS Publisher. He has also served as Editorial board and Scientific Reviewer of the several journal publications that includes IJDT, WASET, IJETSR, IJRDO, among others.

\section{Authors' Profiles}

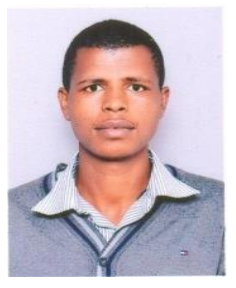

Tilahun Shiferaw is earned his BSc. and MSc. in Information studies and Electronic and Digital Resource Management respectively from Jimma University. He is a lecturer and head of the Department of Information Science under College of Computing and Informatics of Haramaya University, Ethiopia. He has published

How to cite this paper: Tilahun Shiferaw, Patrick D. Cerna,"Cloud Library Framework for Ethiopian Public Higher Learning Institutions", International Journal of Modern Education and Computer Science(IJMECS), Vol.8, No.5, pp.4753, 2016.DOI: 10.5815/ijmecs.2016.05.06 